\title{
Children's Voice and Voice Disorders
}

\author{
Anita McAllister and Peta Sjölander
}

Linköping University Post Print

\section{Tweet}

N.B.: When citing this work, cite the original article.

Original Publication:

Anita McAllister and Peta Sjölander, Children's Voice and Voice Disorders, 2013, Seminars in Speech and Language, (34), 2, 71-79. http://dx.doi.org/10.1055/s-0033-1342978

Copyright: Thieme Publishing / Georg Thieme Verlag http://www.thieme.com/ 


\section{Child voice and voice disorders in children}

\section{Anita McAllister \& Peta Sjölander}

Abstract: This article discusses the differences between children's voices and the adult voice. We give an overview of the anatomy in the head and neck, and specifically the anatomy of the respiratory system and the larynx. We also describe the development of children's voices including different physiological measures and voice quality. The development and consequences for voice production and voice quality are addressed and related to gender differences in the growing child. We also discuss the prevalence of voice problems and hoarseness in children. Environmental and other factors contributing to voice problems in children are described and finally, issues related to intervention and evidence base practice are discussed.

Keywords: Children, voice, development, dysphonia, environment, voice therapy, evidencebased

Learning outcomes: As a result of this activity, the reader will be able to (1) list critical changes in the head, neck, respiratory system, and voice that occur developmentally in girls and boys from infancy to adolescence; (2) identify environmental and other factors that may put a child at risk for a voice disorder; and (3) discuss existing literature on evidence-based reports of voice therapy for children. 


\section{Introduction}

Our knowledge of child voice is still more limited than for the adult voice. One reason is probably that children are more difficult to examine and they are usually not as cooperative as adults. Also, small children may not comprehend the reason for the examination. In many respects children are not just scaled down, smaller versions of adults. Children differ both in body proportions and in the specific anatomy of the respiratory system and the larynx. In this chapter we describe anatomical and physiological development and also the consequences of these differences and development for voice production and voice quality. Voice problems and hoarseness in children are addressed in relation to etiology, typical symptoms and intervention. Finally, environmental factors contributing to voice problems in children are described.

\section{Anatomy}

The newborn baby has a large head, a small mouth and mandible, stabilizing fat pads in the cheeks and the tongue almost fills up the entire oral cavity. The larynx is situated high in the neck in relation to the cervical vertebrae with the cricoid cartilage at the fourth vertebrae (C4), compared to C6 to C7 in adults. This also means a closer relation between the soft palate and the epiglottic cartilage and a shorter vocal tract than for adults. The cartilages and vocal folds in the larynx change as the child matures. These changes involve size, shape and anatomical structures (Kahane 1982). The total length of the vocal folds in a newborn baby has been measured to be between 2.5 and 8 mm (Aronson 1980; Hirano, Kurita, Nakashima 1983). During childhood the evelopment of the vocal folds naturally involves anatomical changes of size but also a change of the relationship between the cartilaginous and membranous portions of the vocal folds. There is also an important change of the internal structures of the vocal folds, e.g., the differentiation into the adult layered structure consisting 
of the epithelium and the superficial layer of lamina propria (LP), followed by the intermediate and the deep layer, and finally the vocalis muscle. In the newborn only a monolayered structure of cells has been found, at five months this has evolved into two layers, and at 7 years a tri-layered structure begins to become evident (Bosley \& Hartnick 2006). The anatomical changes in the vocal folds are gradual and not fully developed until after puberty (Hirano, Kurita, Nakashima 1983). The intermediate layer contains considerable elastin, a fiber that has been shown to stretch up to two times its resting length (Hammond, Gray, Butler, Zhou, Hammond 1998). Also, the depth of the individual layers change with maturation. At seven years of age the total depth of the superficial layer constitutes $22 \%$ of the total depth of lamina propria, a percentage that approximates that of the adult vocal fold (Bosley \& Hartnick 2006).

Anatomical differences affect several aspects of voice production and voice quality. The newborn infant has a fundamental frequency between 400-600 Hz during crying (Michelsson, Michelsson 1999). The cry is the infant's first vocal expression and is modulated into signaling different emotional content to the surroundings during the first year of life. During the first three years of life there is a rather rapid decrease in mean fundamental frequency (F0) for both boys and girls, see figure 1 (Titze 2000). After three years of age, there is a more gradual decrease, until puberty when the mutational voice change occurs. 


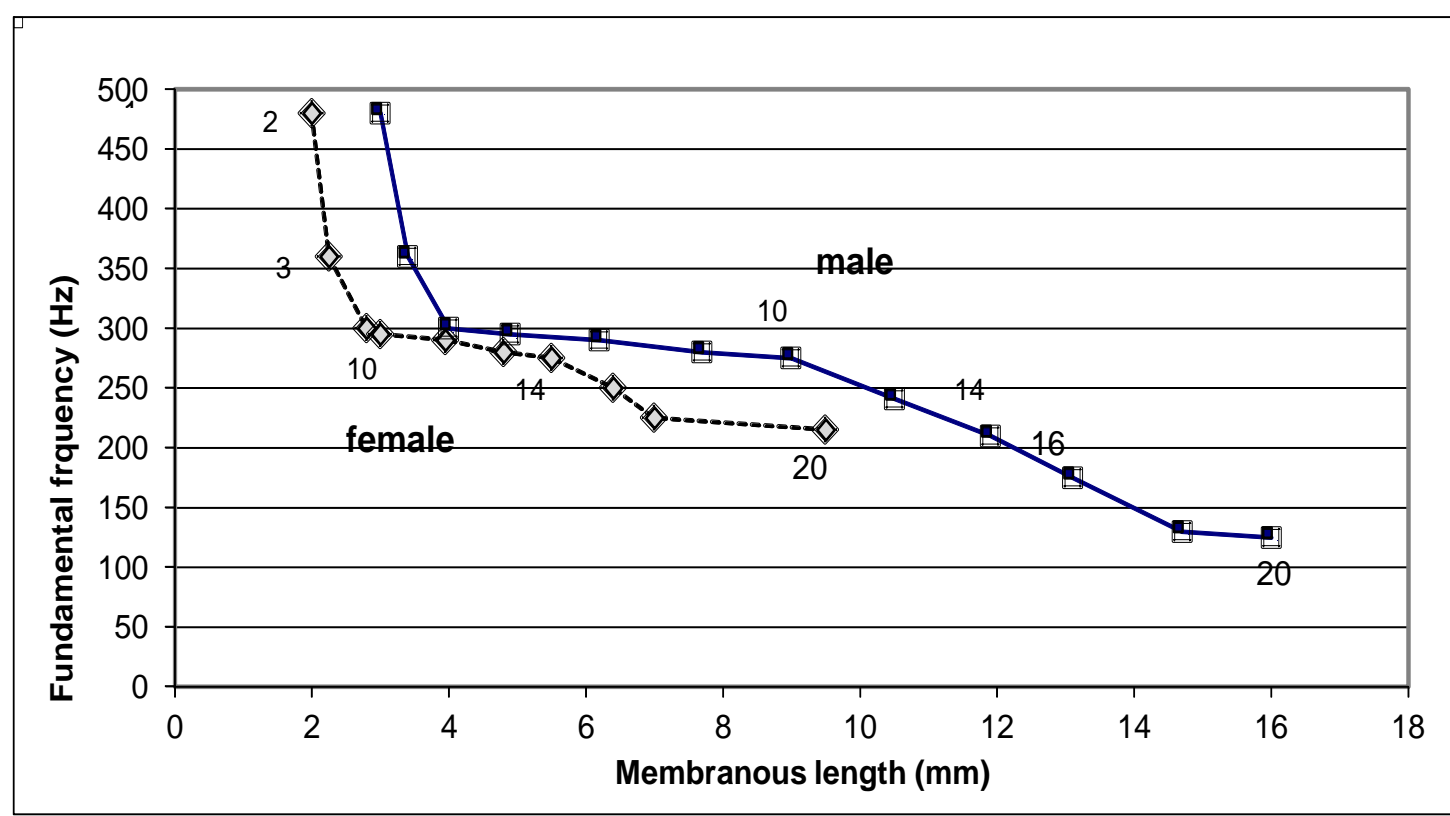

Figure 1. Development of fundamental frequency in boys and girls as a function of membranous length of the vocal fold. After Titze 2000 (p.197 Fig 7.7).

Both boys and girls go through this voice mutation but the change is more apparent in boys. In boys the drop in mean F0 is approximately twelve semitones and in girls three to four semitones (Wilson 1987). There is no one-to-one relationship between vocal fold length and F0, as can be seen in Figure 1, and already at birth boys seem to have a somewhat longer membranous portion of the vocal folds than girls. However, this does not influence F0 to a significant degree until puberty, when there is a rapid growth of the vocal folds. Recent studies of vocal tract growth have found no linear growth patterns and differences in growth between boys and girls (Vorperian et al 2005; 2009).

\section{Gender differences}

Evidence exists that suggests girls and boys adopt gender-specific articulatory and vocal behaviors from early childhood in order to enhance sex distinctions. For instance, a 
perceptual evaluation of the recorded untrained singing voices of 29 children (Sergeant et al, 2005) revealed that experienced listeners, in this case singing teachers, were able to identify correctly and with confidence the sex of the child singing from as young as 4 years of age. Three hundred and twenty voice samples were played over headphones to listeners, who were asked to indicate if they thought they were listening to a girl or a boy and also how confident they were about this decision. The listeners' decisions were well inter-correlated, with a particular group of children being consistently and positively identified as either a boy or girl by each listener.

Perry et al. (2001) similarly found that listeners were able to identify gender from the speech and voice of children as young as four years of age and that, with respect to young children, listeners appeared to base their gender ratings on vowel formant frequencies. Interestingly, in the work by Sergeant et al, (2005) there was a significant relationship between accuracy and age for the identification of boys' voices, a finding which was not seen for girls. In other words, the likelihood of accurately identifying the sex of the subject increased with rising age in boys whereas, for girls, age of the subject had no effect on a correct identification. The younger the boy, the greater the likelihood was that his voice would be wrongly labeled as being that of a girl; girls could be mistaken for boys at any age. This finding is interesting because it suggests that boys’ voices change during this prepubertal period while girls apparently have a more consistent voice quality. It should be noted that a certain group of children in the Sergeant et al. study were consistently misidentified with regard to their sex. In other words, gender identification was consistent but the judgment was faulty.

In a study of 11-year-old experienced singers from a Stockholm music school (White, 1999), it was found that mean formant values (F1 and F2), in both speech and singing, were significantly higher for girls than for boys. Skilled singers are often used in these types of 
studies because they are relatively unfazed by being in a performance situation, and also because they are able to vary pitch while retaining a constant loudness level. Girls and boys at this developmental stage are also quite anatomically similar so it is useful to consider the acoustic differences in this group. In addition, children who have been taught to sing as a group are perhaps more likely to produce vowels that are homogeneous within each category. A finding from this 11-year-old group was that vowel contrasts were significantly modified during singing compared to speech. In other words, when the children were speaking, their vowel formants were different according to their sex. Whilst singing, however, vowel formants showed less difference between girls and boys. This finding is most probably associated with the children's attempts to homogenize their vocal outputs to create a choral blend.

Another dimension in which differences occur between boys and girls is with regard to voice source characteristics (White, 1998). In a group of 11-year-olds, subglottal pressure and flow amplitude were both greater in boys, and boys also demonstrated a greater amount of glottal air leakage during vocal fold closure. It is noteworthy, however, that these findings differ somewhat from those of a similar study (Stathopoulos and Sapienza, 1993).

Using long-term average spectrum (LTAS), it has been established for adults (Sjölander \& Sundberg, 2004) and also for children (White, 1998) that an increase in vocal intensity will increase the amplitude of higher partials relative to lower partials. Averaged across adult subjects, vowels, and F0, a 10-dB increase at $600 \mathrm{~Hz}$ was accompanied by a 16dB increase at $3 \mathrm{kHz}$ in long-term spectra (Sjölander \& Sundberg, 2004). LTAS analysis provides acoustic information averaged over a period of time, typically upwards of 20 seconds, and has the benefit of highlighting the more persistent features of voice production; features that might not be apparent in shorter samples or single vowel productions. One benefit of the method is that the resulting long-term spectrum is not greatly affected by 
differences in speech material, which means comparisons can be made between speakers and even across studies.

The importance of this finding is that the effect on the spectrum of singing at various loudness levels is a factor of some relevance when interpreting acoustic results. The use of skilled singers in these experiments was an attempt to overcome some known challenges faced by the researcher or clinician when faced with young subjects. Interestingly, the increase in intensity of the higher spectrum partials found in the children was greater for girls than for boys. It is not easy to interpret this finding, and more studies are needed.

\section{Adolescent voice}

The most dramatic voice change occurs during puberty. A question that remains somewhat open is "What is normal for adolescent voice, and what should be considered deviant?” The voice change during teen years, most noticeable in boys, is a period lasting several months or even years. The modern myth is that a boy wakes up one morning to a new, adult voice, one octave lower than that of the previous day. But, although we know this is not so, we are less clear about when or how the voice change actually occurs. The simple answer is that the experience is not the same in any two persons. An adult-sounding voice might be quite apparent in one 14-year-old, but not in the boy who sits alongside him in the classroom and who was born in the same month, as the mutational voice change depends on hormonal change and physical development rather than age. Thus, the average speaking pitch of the first boy might be an octave lower than the second. In males, growth of the structures involved is up to $60 \%$ between pre-puberty and adult dimensions (Kahane 1982). Additionally during this period, voice quality is of some concern to some children and their parents. More scientific research results are needed to be able to fully understand the changes and timings, but we know that in singers, the vocal range reduces somewhat with higher pitches becoming more 
McAllister \& Sjölander

and more difficult to achieve (Cooksey, 1993). Once adult voice is reached, such high notes will only be available by using a falsetto voice. The growth of the larynx and other structures occurs at a fast rate compared to other periods of childhood (except during infancy) meaning such growth may influence voice control, leading to the "warbling” and “croaking” characteristics often observed during this time. Further into the period of adolescent voice change, the child is able to produce increasingly lower pitches at the bottom of the range. Average speaking F0 also decreases as a result of the anatomical changes. The process is similar for girls, but with less dynamic changes.

\section{Voice quality and vocal measurements}

Perceptual assessments of childrens' voice quality have revealed that boys’ voices are typically more hyperfunctional than girls, and that girls have a higher degree of breathiness compared to boys (Sederholm McAllister, Sundberg, \& Dahlqvist 1993; McAllister et al., 1994; McAllister et al., 2009). Incomplete glottal closure is also a common finding in women, especially younger women (Beiver \& Bless 1989; Södersten \& Lindestad, 1990).

Vocal characteristics may be assessed using different instruments. However it can be assumed that voice quality is perceived along a continuum rather than in a stepwise fashion, and thus the use of continuous visual analogue scale (VA-scales) offers more detailed information than typical ordinal scales (Sederholm et al. 1993). Studies of voice quality using VA-scales have also enabled an estimate of the perceptual boundary between normal and deviant voice for a specific parameter (Sederholm 1995). This distinction appears as an elbow in the rank ordered mean values of a voice trait and is followed by a changed direction of the distribution (see Figure 2). 


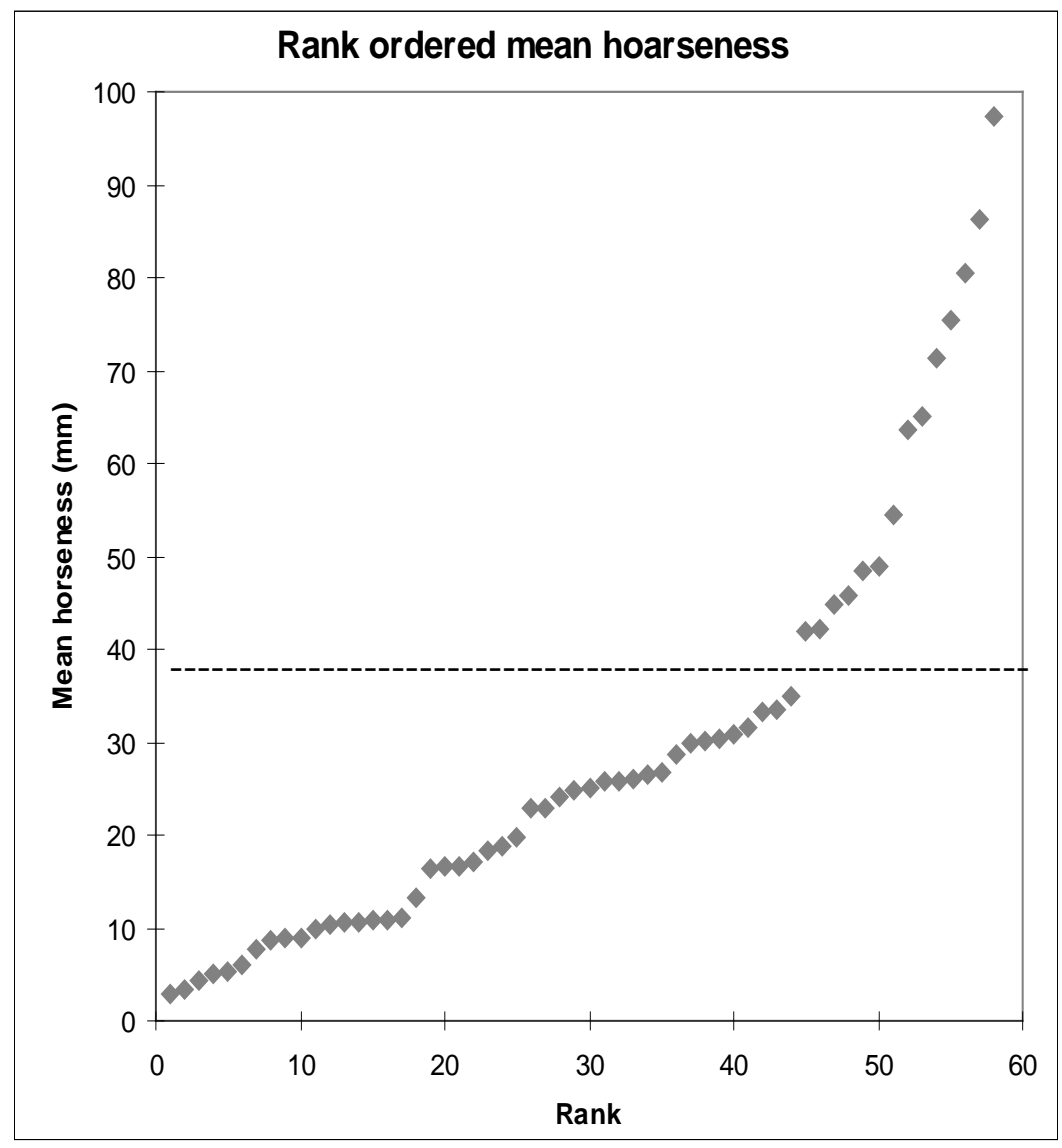

Figure 2. Rank ordered mean hoarseness of 58 children's voices. The elbow in the distribution is marked by the dotted line.

Differences in size in the respiratory system have also been found to influence breathing patterns and so-called breath support in speech. Stathopoulos and Sapienza (1993) found that 4- and 8year old children had higher tracheal pressures during speech compared to adults. The children also used more of their vital capacity, with a greater rib-cage displacement than adults (Stathopoulos, Sapienza1993; 1997). Higher subglottal pressures than in adults have also been found in younger children 3:3 - 4:3 years old (Netzell, Lotz, Peters, Schulte 1994). However, a study of subglottal pressures at threshold and at normal and loud phonation in 8- to 11-yearold children found values similar to adults (McAllister, Sundberg 1998).

Several studies of children's vocal range as documented in a voice range profile (VRP) -which plots smallest and greatest intensity over fundamental frequency across a person’s Fo range -- 
McAllister \& Sjölander

have reported that children have a somewhat elevated lower VRP contour compared to adult voices and sometimes a more restricted dynamic range (Kotby, Orabi 1995). That is, it appears children are not able to be as quiet as adults, when they try. The VRP contours have been suggested to reflect structural and functional properties of the vocal folds. Thus, the lower contour could reflect the ability of the mucosa to vibrate at low pressures while the upper contour would depend on the capacity of the vocalis muscle to cope with high pressures (Gramming \& Sundberg 1988). Böhme and Stuchlik (1995) studied 277 children 5 to 14 years old, however standard VRP values could not be obtained for children below 7 and above 10 due to inconsistencies in the VRP registration. Their results were in accordance with previous studies showing a somewhat elevated lower contour especially in boys. This may indicate a stiffer vocal fold mucosa in boys compared to girls or that their muscular and sensory control is not fully developed causing them to use higher subglottal pressures than required for phonation. However, a more recent study aiming at establishing normative VFP data for children could not corroborate these gender differences (Wuyts, Heylen, Mertens, De Bodt, Van de Heyning 2002).

Vocal pitch range in children without voice disorders has been found to be around two octaves or 24 semitones (ST) (for an overview of vocal range in children see Wilson 1987). In a study of 10-year-old children's voices, the vocal range in children with normal voices and vocal fold status was 25 ST, whereas in children with vocal nodules and chronic hoarseness the fundamental frequency range was somewhat restricted with 19 and 22 ST respectively. Children with incomplete glottal closure and mutational voices had a slightly larger vocal range with 27 and 29 ST respectively (McAllister et al 1994)

With regard to children's acoustic voice characteristics some studies suggest that perturbation measures represent perceptually relevant information (Oates \& Kirkby 1980; Kane \& Wellen, 1985; Glaze et al., 1988; McAllister, Sundberg, Hibi 1998). Usually correlations between acoustic and perceptual assessments are moderate. This is to be expected since several individual, cultural and social factors influence listeners’ perceptual ratings as 
well as perceived perceptual relevance of various aspects of the signal and the limitations of our hearing system. However, since voice and voice quality are perceptual by nature, perceptual voice characteristics have greater intuitive meaning than many instrumental measures (Oates, 2009).

Stathopoulos and Sapienza (1993) found that a doubling of subglottic pressure (Ps) yielded an $11 \mathrm{~dB}$ increase for a group of adults and a $16 \mathrm{~dB}$ increase for 8-year-old children. In a study of nine children 8 - 11 years old a doubling of Ps yielded a $10.8 \mathrm{~dB}$ increase, similar to adult measures (McAllister, Sundberg 1998). A child with acute hoarseness also participated in this investigation. He exhibited clearly elevated Ps as compared to the rest of the group, with a mean Phonation Threshold Pressure (Pth) value that was almost twice of the other subjects, and that substantially increased with F0.

\section{Voice problems in children}

Deviant voice quality is an indication that the child has a functional or organic voice disorder. The assessment of a voice disorder should include a laryngoscopic examination with videostroboscopy to assess vocal fold closure and mobility of the vocal fold cover and cartilages. In the voice clinic, the diagnosis of dysphonia is made based on perceptual evaluations of voice quality and vocal fold vibration through a standardized procedure with a laryngoscopic, videostroboscopic, or highspeed video examination, sometimes complemented by acoustic or aerodynamic measures (Hartnic, Boseley 2008). Usually a recording of the child reading or repeating short sentences is also made in connection to the examination. Based on this documentation a decision regarding intervention is made by the clinician, the child and the parent in cooperation. The child's own perception of the problem is very important to consider. Does he or she feel there is a problem at all? Is the problem noticeable enough to motivate him/her for therapy? An aide in appraising children’s and parents perception of a voice problem and its impact for the specific child is the pediatric Voice 
Handicap Index (pVHI) consisting of 23 statements over three domains; Functional, Physical and Emotional (Zur et al 2007). A hoarse dysfunctional voice may also influence the listeners' opinion the child (Sederholm et al. 1995). Taken together, these observations should indicate whether a voice disorder may influence the child's quality of life (Boseley, Cunningham, Volk, Hartnick 2006). In some cases, where it is clear to clinicians, parents, or others that the child has a voice problem, but the child does not appear particularly aware or concerned about it, it may be that the child simply does not have the language to express concerns. In those cases, it may be important for clinicians to "set the stage" for the child, describing voice and voice problems with age-appropriate stories and illustrations.

Some information is available on the prevalence of voice disorders in the pediatric population. Carding, Roulstone, Northstone (2006) examined the prevalence of dysphonia in a large cohort of children $(n=7389)$ at 8 years of age. The prevalence of dysphonia according to research clinicians was $6 \%$ compared to a parental report of $11 \%$. Identified risk factors for childhood dysphonia are having older siblings, male gender, and spending long days in large groups (Carding et al., 2006; Sederholm et al 1993; Sederholm et al., 1995). After puberty voice disorders are more prevalent in women than in men (Yu, Garrel, Nicollas, Ouaknine, Giovanni 2007). Together, these findings may indicate that it is important to identify and treat not only boys but also girls with a voice disorder.

In the same study, parental reports suggested a link between and asthma and tonsillectomy, whereas common upper respiratory or other otolaryngological conditions were not linked to voice problems (Carding et al, 2006). In a Swedish study of 205 10-year-old children from different parts of the country, the prevalence of hoarseness was $14 \%$ (Sederholm 1995). Higher figures were found in larger cities compared to the rest of the country. These figures are somewhat higher than the study from the United Kingdom (UK), 
however the number of children attending pre-schools and after school care is $92 \%$ in Sweden (UNICEF 2008) compared to 66,5\% in the UK (UNESCO 2008).

The reason for the high prevalence of voice disorders in children is surely multifactorial including different combinations of developmental, personal and environmental factors. The lack of the protective three-layered structure of the vocal ligament in the immature vocal folds has been proposed to make children more prone to tissue reactions because of heavy voice use (Sédlacková 1960; Casper, Colton, Leonard 2006). Also shortterm group activities such as a summer camp have been found to affect vocal quality in children. A study of voice quality showed increased hoarseness on camp termination compare to at the start of the camp (Casper, Abramson, Forman-Franco 1981).

Several aspects of the speech spectrum including F0 and other parameters related to voice quality have been reported to be negatively affected by enlarged tonsils (Henningsson \& Isberg, 1988; Maryn, Van Lierde, De Bodt, \& Van Cauwenberge, 2004; Mora et al., 2007; Lundeborg et al. 2012). According to a recent study these differences disappeared after tonsillectomy (Lundeborg et al. 2012).

\section{Environmental factors influencing vocal behavior}

High background noise levels have been documented in pre-schools and schools, ranging between 72 and 80 dBA during an 8-hour working day (Truchon-Gagnon, Hétu 1988; Shield, Dockrell 2004; Södersten, Granqvist, Hammarberg, Szabo 2002). Background noise has been found to influence several vocal parameters such as loudness, subglottal pressure, fundamental frequency, voice quality and speech comprehension (Gramming, Sundberg, Ternström, Leanderson, Perkins 1988; Stemple, Stanley, Lee 1995; Rantala, Määttä, Vilkman 1997; Crandell, Smaldino 2000; Södersten et al 2002; Vilkman, Alku Vinturi 2002; Södersten, Ternström, Bohman 2005). Also, children seem to be more bothered by 
McAllister \& Sjölander

background noise than adults. In a study of effects of age on speech perception kindergarten aged children need a better signal-to-noise ratio than adults and their older peers to obtain equal comprehension (i.e, much louder speech level than the level of interfering noise) (Marshall, Brandt, Marston, Ruder 1979).

A field study of three day care centers found that the mean background noise level, using a binaural recording technique, was $82.6 \mathrm{dBA}$ Leq, ranging from 81.5 to $83.6 \mathrm{dBA}$ Leq at the different centers (McAllister, Granqvist, Sjölander, Sundberg 2009). The perceptual evaluation of voice quality from recordings of children attending the day care center with the highest noise levels also revealed higher ratings of hoarseness, breathiness, and hyperfunction than in centers with lower noise levels. Girls increased their loudness level during the day, but for boys no such change was observed. These results point to the importance of studying vocal behavior in natural everyday life situations (Södersten et al. 2002; Vilkman 2004).

\section{Intervention}

Most intervention for voice disorders in children addresses several potentially detrimental vocal behaviors in a step-by-step procedure (Andrews 1986; Sederholm, McAllister 2000; Nienkerke-Springer, McAllister, Sundberg 2005). The aim of the intervention is to raise the child's awareness of his or her own voice production and vocal hygiene. Specific aims may address breathing patterns, habitual pitch and loudness and seeking to decrease tension and vocal effort when speaking. Usually also listening and attention exercises are included. In our personal experience, the intervention is often organized in weekly sessions with small groups of children of similar ages. Pre-pubertal children may also be grouped according to gender. The sessions are followed up by weekly homework assignments. Home practice may be documented in a parent/child diary. For younger children, the intervention needs to be playful and incorporated into games or short 
play exercises. To raise awareness, the intervention program could start with the children themselves describing or drawing pictures of how the voice feels when it is ok and when it is not. These mental images can serve as a comparison and a reminder later in the therapy. The children need to learn to use non-harmful vocal behavior in everyday communication. They also need to become aware of situations when they overuse their voices and find suitable strategies to minimize the detrimental effects. Children with an interest in singing benefit from a cooperation between singing teacher and speech-language pathologist. In some cases the intervention may also need to include family members to address all aspects of the problem and help the child (Nienkerke-Springer et al. 2005). Alternative and complementary approaches to the general one described here are detailed in other articles in this issue.

When searching the open access database SpeechBITE for studies reporting on best and most effective interventions for children with voice disorders, the total number of matching items are 22 (http://www.speechbite.com/list.php 2013). Most studies are case studies, two are systematic reviews and one is a randomized controlled trial indicating the need for reports on outcome of voice therapy for children.

\section{Conclusions}

Differences in anatomy in the head and neck, larynx and the vocal folds affect several aspects of children's' voices. This is especially evident in the newborn infant. Differences between boys and girls have been found already during pre-school years. During puberty boys F0 drop approximately 12 ST and girls F0 drop 3 to 4 ST. High background noise levels have been found in pre-schools and schools. Children need a better signal-to-noise ratio than adults and older peers to have equal speech comprehension. The evidence base aiding our choice of intervention for children with voice disorders is still lacking. 
McAllister \& Sjölander 


\section{References}

Andrews, M. L. (1991). Voice therapy for children. San Diego: Singular Publishing.

Aronson A. (1980)Clinical voice disorders. An interdisciplinary approach. New York ThiemeStratton Inc.

Beiver D M, Bless D M. (1989).Vibratory characteristics of the vocal folds in young adult and geriatric women. J Voice, 3;2: 120-31.

Boseley, M. E., Cunningham, M. J., Volk, M. S., \& Hartnick, C. J. (2006). Validation of the pediatric voice-related quality-of-life survey. Archives of Otolaryngology--Head \& Neck Surgery, 132(7), 717-720.

Boseley ME, Hartnick CJ. (2006). Development of the human true vocal fold: depth of cell layers and quantifying cell types within the lamina propria. Ann Otol Rhinol Laryngol. 115;10:784-8.

Böhme G, Stuchlik G (1995). Voice profiles and standard voice profiles of untrained children, $J$ Voice, 9: 304-307.

Carding, P.N., Roulstone, S., \& Northstone, K. (2006) The prevalence of childhood dysphonia: a cross-sectional study. ALSPAC Study Team. Journal of Voice, 20(4), 623-630.

Casper M, Abramson AL, Forman-Franco B. (1981). Hoarseness in children: summer camp study. Int Pediatr Otorhinolaryngol.3:85-89.

Casper J, Colton RHK, Leonard R. (2006). Understanding Voice Problems. $3^{\text {rd }}$ ed.). Baltimore: Lippincott Williams \& Wilkins.

Cooksey JM (1993) Do adolescent voices ‘break' or do they ‘transform’? Voice, the Journal of the British Voice Association, 2(1), 15-39.

Crandell CC, Smaldino JJ. (2000). Classroom acoustics for children with normal hearing and with hearing impairment. Lang Speech Hear Serv Sch. 31:362-370.

Glaze LE, Bless DB, Milenkovic P, Susser RD (1988). Acoustic characteristics of children's voice. J Voice, 2/4: 312-319.

Gramming P, Sundberg J (1988). Spectrum factors relevant to phonetogram measurement. J Acoust Soc Am, 83: 2352-2360.

Gramming P, Sundberg J, Ternström S, Leanderson R, PerkinsW. (1988). Relationship between changes in voice pitch and loudness. $J$ Voice. 2:118-126.

Hammond TH, Gray SD, Butler J, Zhou R, Hammond E. (1998). Age- and gender-related elastin distribution changes in human vocal folds. Otolaryngol Head Neck Surg. 119:314-322.

Hartnick, C., \& Boseley, M. (2008). Pediatric voice disorders. San Diego: Plural Publ.

Henningsson, G., \& Isberg, A. (1988). Influence of tonsils on velopharyngeal movements in children with craniofacial anomalies and hypernasality. Am J Orthodontics and Dentofacial Orthopedics, 94 (3), 253-261. 
Hirano, M., Kurita, S., \& Nakashima, T. (1983). Growth, development and aging of human vocal folds. In D. M. Bless, \& J. H. Abbs (Eds.), Vocal fold physiology : Contemporary research and clinical issues (pp. 22-43). San Diego: College-Hill Press.

Kahane J. (1982). Growth of the human prepubertal and pubertal larynx. J Speech Hear Res, 25:446455.

Kane M, Wellen CJ (1985). Acoustical measurements and clinical judgments of vocal quality in children with vocal nodules. Folia Phoniatrica, 37: 53-57.

Kent R D, Vorperian H K. (1995) Development of the craniofacial-oral-laryngeal anatomy: A review. J Medical Speech Language Pathology, 3:3, 145-90.

Kotby MN, Orabi AA (1995). Voice range profiles as a quantitative measure of vocal function in some pathological voices. In Kotby M. (Ed). Congress Proceedings of XXIII IALP Congress, Cairo.

Lundeborg I, Hultcrantz E, Ericsson E, McAllister A (2012). Acoustic and perceptual aspects of vocal function in children with adenotonsillar hypertrophy. Effects of surgery. $J$ Voice. 26(4):480-487

Marshall L, Brandt JF, Marston LE, Ruder K. (1979). Changes in number and type of errors on repetition of acoustically distorted sentences as a function of age in normal children. $J$ Am Aud Soc.4:218-225.

Maryn, Y., Van Lierde, K., De Bodt, M., \& Van Cauwenberge, P. (2004). The effects of adenoidectomy and tonsillectomy on speech and nasal resonance. Folia Phoniatrica et Logopedica, 56(3), 182-191.

McAllister A. Granqvist S, Sjölander P, Sundberg J. (2009). Child Voice and Noise: A Pilot Study of Noise in Day Cares and the Effects on 10 Children's Voice Quality According to Perceptual Evaluation. $J$ Voice. 23: 5, 587-593

McAllister A, Sederholm E, Sundberg J, Gramming P (1994): Relations between Voice Range Profiles and Physiological and Perceptual Voice Characteristics in Ten-year-old children. $J$ Voice 3:230239.

McAllister, A., Sundberg, J. (1998): Data on subglottal pressure and SPL at varied vocal loudness and pitch in 8-11 year old children. $J$ Voice 12, 166-174

McAllister, A., Sundberg, J, Hibi S. (1998): Acoustic measurements and perceptual evaluation of hoarseness in children's voices. Log Phon Vocol, 23: 27-38.

Michelsson K, Michelsson O. (1999). Phonation in the newborn, infant cry. International Journal of Pediatric Otorhinolaryngology. 49 Suppl. 1:297-301 
Mora, R., Crippa, B., Dellepiane, M., \& Jankowska, B. (2007). Effects of adenotonsillectomy on speech spectrum in children. Int J Pediatric Otorhinolaryngology, 71(8), 1299-1304.

Netsell, R., Lotz, W. K., Peters, J. E., \& Schulte, L. (1994). Developmental patterns of laryngeal and respiratory function for speech production. $J$ Voice, 8, 123-131.

Nienkerke-Springer, A., McAllister, A., Sundberg, J. (2005). Effects of family therapy on children's voices. J Voice. 19:1:103-113

Oates, J. (2009). Auditory-perceptual evaluation of disordered voice quality: pros, cons and future directions. Folia Phoniatrica et Logopedica, 61(1), 49-56.

Oates JM, Kirkby RJ (1980). An acoustical investigation of voice quality disorders in children with vocal nodules. Australian J Human Comm Dis, 8/1: 28-39.

Perry TL, Ohde RN, Ashmead DH (2001). The acoustic bases for gender identification from children’s voices, J Acoust Soc Am, 109(6), 2988-98.

Rantala L, Määttä T, Vilkman E. (1997). Measuring voice under teachers working circumstances: F0 and perturbation features in maximally sustained phonation. Folia Phoniatr Logop.49:281-291.

Sédlacková E. (1960). Les dysphonies hypercine'tiques des enfants, cause'es par surmenage vocal. Folia Phoniatr.12:48-60.

Sederholm E, McAllister A, Sundberg J, Dalkvist J. (1993). Perceptual evaluation of hoarseness using continuous scales. Scand J Logop Phoniatr.18: 73-82.

Sederholm E, McAllister A, Dalkvist J, Sundberg J. (1995). Aetiologic factors associated with hoarseness in ten-year-old children. Folia Phoniatr Logop. 1995;47(5):262-78.

Sederholm, E., McAllister, A. (2000). Group therapy for dysphonic children. In Child Voice, ed Peta White, KTH Voice Center, 143-147, ISBN 91-7170-512-0

Sergeant DC, Sjölander PJ, Welch GF (2005). Listeners’ identification of gender differences in children’s singing. Research in Music Education, 24, 28-39.

Shield B, Dockrell JE. (2004). External and internal noise surveys of London primary schools. $J$ Acoust Soc Am.115:730-738.

SpeechBITE $^{\text {TM }}$ http://www.speechbite.com/list.php 2013-02-11, 19.30 CET

Stathopoulus E.T., Sapienza C. (1993). Respiratory and laryngeal measures of children during vocal intensity variation. $J$ Acous Soc Am. 94;5:2531-41.

Stathopoulus E.T., Sapienza C. (1997). Developmental changes in laryngeal and respiratory function with variation in sound pressure level. JSLHR. 40;595-614. 
Stemple JC, Stanley J, Lee L. (1995). Objective measures of voice production in normal subjects following prolonged voice use. $J$ Voice. 9:127-133.

Sjölander P, Sundberg J (2004) Spectrum effects of subglottal pressure variation in professional baritone singers, J Acoust Soc Am, 115(3), 1270-1273.

Södersten M, Granqvist S, Hammarberg B, Szabo A. (2002). Vocal behaviour and vocal loading factors for preschool teachers at work studied with binaural DAT-recordings. $J$ Voice. 16:356371.

Södersten, M. \& Lindestad, P-Å. (1990). Glottal closure and perceived breathiness during phonation in normally speaking subjects. J Speech Hear Res, 33: 601-611.

Södersten M, Ternström S, Bohman M (2005). Loud speech in realistic environmental noise: phonetogram data, perceptual voice quality, subjective ratings and gender differences in healthy speakers. $J$ Voice, 19(1):29-46.

Titze, I R. (2000). Voice classification and life-span changes. In Principles of Voice Production. Second ed. National Center for Voice and Speech, Iowa City, IA.

Truchon-Gagnon C, He'tu R. (1988). Noise in day-care centers for children. Noise Control Eng J. 30:7-64.

UNESCO Institute for Statistics, Data Centre, http://stats.uis.unesco.org/unesco/ReportFolders/ReportFolders.aspx, January 2008.

UNICEF, Division of Policy and Practice, Statistics and Monitoring Section, www.childinfo.org, May 2008.

Vilkman E. (2004). Occupational safety and health aspects of voice and speech professions. Folia Phoniatr Logop.6:220-253.

Vilkman E, Alku Vinturi. (2002). Dynamic extremes of voice in the light of time domain parameters extracted from the amplitude features of glottal flow and its derivative. Folia Phoniatr Logop. 54:144-157.

Wilson, K D. (1987). Voice Problems of Children. Third ed. Williams \& Wilkins, Baltimore, MD.

Vorperian, H. K., Wang, S., Chung, M. K., Schimek, E. M., Durtschi, R. B., Kent, R. D., Ziegert, A. J., Gentry, L. R. (2009). Anatomic development of the oral and pharyngeal portions of the vocal tract: An imaging study. J Acoust Soc Am. 125(3), pp. 1666-1678

Vorperian H. K, Kent R. D, Lindstrom M. J, Kalina C. M, Gentry L. R, Yandell B. S. (2005).

Development of vocal tract length during early childhood: A magnetic resonance imaging study. J Acoust Soc Am. 117;1: 338-350 
McAllister \& Sjölander

White P (1998) A study of the effects of vocal intensity variation on children's voices using long-term average spectrum (LTAS) analysis. Log Phon Vocol, 23, 111-120.

White P (1999) Formant frequency analysis of children's spoken and sung vowels using sweeping fundamental frequency production, $J$ Voice, 13(4), 570-582.

Wuyts FL, Heylen L, Mertens F, De Bodt M, Van de Heyning P H. (2002). Normative Voice Range Profiles of Untrained Boys and Girls. J Voice. 16; 4: 460-465

Yu P, Garrel R, Nicollas R, Ouaknine M, Giovanni A. (2007). Objective voice analysis in dysphonic patients: new data including nonlinear measurements. Folia Phoniatr Logop.59:20-30.

Zur, K. B., Cotton, S., Kelchner, L., Baker, S., Weinrich, B., \& Lee, L. (2007). Pediatric voice handicap index (pVHI): A new tool for evaluating pediatric dysphonia. International Journal of Pediatric Otorhinolaryngology, 71(1), 77-82. 